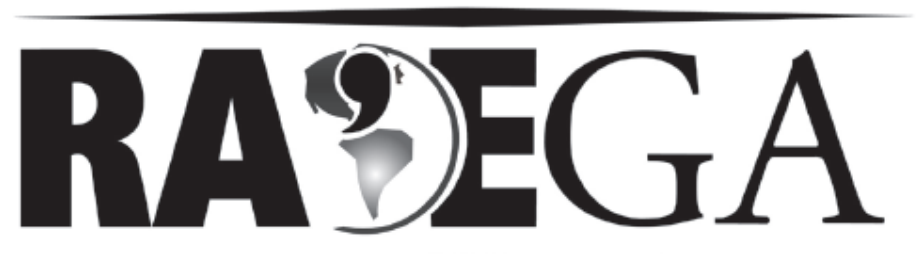

O ESPAÇO GEOGRÁFICO EM ANÁLISE

\title{
VULNERABILIDADE HÍDRICA NA BACIA SERGIPANA DO RIO VAZA BARRIS
}

\section{WATER VULNERABILITY IN THE VAZA BARRIS RIVER BASIN IN SERGIPE}

\author{
Márcia Eliane Silva Carvalho ${ }^{1}$
}

\section{RESUMO}

Este artigo tem como objetivo apresentar indicadores que possam avaliar a vulnerabilidade hídrica em bacia hidrográfica em função de agentes naturais e/ou antrópicos. Para tal, foi tomada como estudo de caso a porção sergipana da bacia do rio Vaza Barris. A associação dos indicadores escolhidos compôs um quadro acerca da vulnerabilidade hídrica, demonstrando que as limitações naturais impostas pelo ambiente (principalmente as relativas aos aspectos hidrogeológicos, pedológicos e climáticos) podem ser potencializadas pelas pressões antrópicas, traduzidas aqui pelas formas de utilização das terras, expressando as inter-relações sociedade e natureza construídas historicamente ao longo do processo de ocupação deste espaço.

Palavras-chave: Vulnerabilidade; Pressões Antrópicas; Recursos Hídricos; Bacia Hidrográfica

\footnotetext{
${ }^{1}$ Graduada em Biologia, Especialista em Gestão de Recursos Hídricos e Meio Ambiente, Mestrado e Doutorado em Geografia pela UFS. Professora Adjunta do Departamento de Geografia da Universidade Federal de Sergipe, Campus Prof. Alberto Carvalho. Aracaju/SE/Brasil. e-mail: marciacarvalho@ufs.br
} 


\section{ABSTRACT}

This article aims to present indicators that can assess the water vulnerability in drainage basin in terms of natural and/or anthropogenic agents. To this end, it was taken as case study the Sergipe portion of the Vaza Barris River basin. The association of the chosen indicators composed a framework of the water vulnerability, demonstrating that the natural limitations imposed by the environment (especially the aspects relating to hydrogeology, soils and climate) can be intensified by human pressures, translated here by the forms of land use, expressing the inter-relationship between society and nature historically constructed along the process of occupying this space.

Keywords: Vulnerability; Human Pressures; Water Resources; Drainage Basin

\section{Introdução}

Os recursos hídricos enquanto componente físico e fundamental na produção do espaço condiciona, com algumas exceções, a localização de núcleos populacionais, indústrias, usinas hidrelétricas, empreendimentos agrícolas e de aqüicultura, bem como atividades voltadas para a pesca, o esporte e o lazer.

Estes usos denotam o caráter eminentemente geográfico das águas, pois ao mesmo tempo em que é um recurso da natureza é também base indispensável do desenvolvimento da sociedade. Em outras palavras, a água exprime a relação direta e indissociável entre sociedade e natureza.

Em contrapartida, em função do incremento populacional e do desenvolvimento técnico-científico, tem crescido cada vez mais a exploração e/ou deterioração dos recursos hídricos para satisfazer as necessidades de origem antrópica.

Nestes termos, a bacia hidrográfica tem sido destacada por vários autores (dentre eles, LEAL, 1995, 2000; LANNA, 1995; CARRERAFERNANDEZ, 2002; CAMPOS, 2003; MACHADO, 2003, 2004; TUNDISI, 2005; SILVA e PRUSKI, 2005) como a unidade territorial de planejamento e gestão dos recursos hídricos devido à repercussão integrada dos agentes naturais e antrópicos nesta unidade territorial. 
Identificada como "célula básica de análise ambiental" (BOTELHO e SILVA, 2004, p. 153), a bacia hidrográfica apresenta as interações entre o físico e o antrópico, sendo que ao adotá-la como unidade de planejamento está implícita a adoção de uma abordagem metodológica sistêmica.

Os processos que ocorrem na bacia hidrográfica irão repercutir de alguma forma nos recursos hídricos superficiais e/ou subterrâneos. As condições climáticas, a cobertura vegetal, o embasamento geológico e a ação antrópica são alguns dos fatores que podem contribuir para uma maior ou menor vulnerabilidade hídrica.

Compreende-se que para analisar a vulnerabilidade hídrica deve-se tomar como pressuposto o fato de que há uma intrínseca relação entre os condicionantes ambientais de um determinado espaço geográfico que irão determinar a vulnerabilidade hídrica local e a sociedade ali instituída, cujas condições de vida, estrutura institucional, econômica e política irão, em conjunto, determinar os usos e/ou desuso das águas, evidenciando o caráter socioambiental desta questão.

Neste sentido, este estudo apóia-se na abordagem socioambiental que propõe superar a insuficiência de tratar os problemas ambientais somente sob o enfoque natural: "(...) um estudo elaborado em conformidade com a geografia socioambiental deve emanar de problemáticas em que situações conflituosas, decorrentes da interação entre a sociedade e a natureza, explicitem a degradação de uma ou de ambas" (MENDONÇA, 2004, p. 134).

Neste sentido, busca-se, a partir do entendimento que a vulnerabilidade hídrica tem forte conotação socioambiental, compreender as relações estabelecidas entre sociedade e natureza na bacia hidrográfica em estudo.

Para tal, Leff (2009, p.146) traz uma importante contribuição acerca desta questão:

A desorganização ecossistêmica do planeta e a crescente entropia dos processos produtivos, guiados pela razão tecnológica e pela lógica do mercado, criaram necessidades de enfoques integradores do conhecimento para compreender as causas e dinâmicas de processos socioambientais que, por sua complexidade, excedem a capacidade de conhecimento 
dos paradigmas científicos dominantes, exigindo uma recomposição holística, sistêmica e interdisciplinar do saber.

Especificamente sobre a vulnerabilidade é importante destacar que 0 termo tem sido definido por distintos autores a partir de diferentes acepções. Hogan et al. (2001) afirmam que existe pouco consenso entre os pesquisadores sobre uma definição única para o termo. Cutter (1996, apud Hogan et al.) realizou uma revisão do termo e propôs a seguinte categorização: vulnerabilidade como condição pré-existente, vulnerabilidade como resposta moderada e vulnerabilidade como risco do lugar. Esta última se aproxima mais do entendimento adotado neste trabalho.

Ao mesmo tempo, vários trabalhos buscam compreender a vulnerabilidade em diferentes ambientes. Como por exemplo, Augé (2005) aborda a questão da vulnerabilidade de aqǘferos, Tagliani (2003) a vulnerabilidade em ambientes costeiros, Crepani et al. (1996) associam a vulnerabilidade aos processos erosivos e Marengo (2008) aborda a vulnerabilidade climática no semi-árido brasileiro.

Especificamente sobre a vulnerabilidade hídrica em bacias hidrográficas, pode-se tomar como referência a proposta da USEPA - United States Environmental Protection Agency (2001, 2002 apud MAGALHÃES JÚNIOR, 2007) a qual apresenta indicadores de estado/pressão/vulnerabilidade para a avaliação das águas em bacias hidrográficas. No entanto, esta proposta apresenta-se complexa em função da necessidade de vários e específicos dados municipais que dificultam a sua elaboração e que fogem das informações disponíveis para muitas bacias hidrográficas, necessitando de estudos detalhados em nível municipal.

Considerando o exposto, este artigo tem como objetivo apresentar indicadores que possam avaliar a vulnerabilidade hídrica em bacia hidrográfica, tomando como estudo de caso a porção sergipana da bacia do rio Vaza Barris, visando, ao mesmo tempo, identificar neste espaço quais setores apresentam uma maior ou menor pressão sobre os recursos hídricos em função de agentes naturais e/ou antrópicos. 
Para tal, foram tomadas como base as considerações metodológicas de Magalhães Júnior (2007), Pinto (1997) e Ross (1994), somados a dados constantes no IBGE (2006, 2007), Cunha (2002), SEPLANTEC/SRH (2004), CPRM (2002) e PNUD (2000).

Para a elaboração das cartas temáticas foi utilizada a base de dados do Atlas Digital sobre Recursos Hídricos de Sergipe da SRH (2004) transposta para os programas Arcview GIS 3.2, Spring 4.3 e o CorelDRAW X3. As informações constantes nas cartas foram associadas e complementadas com as atividades de campo.

Para o estudo do clima, foram tomados seis municípios considerados representativos para os diferentes tipos climáticos na bacia: Carira, Frei Paulo - representando o Alto-baixo curso; Itabaiana e Campo do Brito - referente ao Médio-baixo curso; Itaporanga d'Ajuda e Aracaju - representando o Baixo curso.

Os dados de precipitação pluviométrica foram obtidos na EMDAGRO (1985-1997; 2001-2008), SEPLANTEC (1970 a 2000), COHIDRO (1985-1997) e SUDENE (1970-1984).

A caracterização hidrogeológica apoiou-se em dados do Atlas Digital de Recursos Hídricos (SRH, 2004), associando aos dados constantes no Projeto de Cadastro da Infra-estrutura Hídrica no Nordeste (CPRM, 2002).

Os dados relacionados com a população residente, densidade demográfica, crescimento populacional, grupos de idade, renda, características dos domicílios quanto à forma de abastecimento e tratamento de água e esgotamento sanitário foram baseados nas informações constantes no Sistema de Atenção Básica de Sergipe (SIAB, 2007), Atlas do Desenvolvimento Humano do Brasil (PNUD, 2000), Contagem de População (IBGE, 2007), Censos Demográficos do IBGE de 1991 e 2000, e nos Perfis Municipais (2002).

A análise sobre as disponibilidades hídricas da bacia baseou-se nas pesquisas sobre Desenvolvimento de Recurso Hídrico no Estado de Sergipe (JICA, 2000), Disponibilidade Hídrica nas Unidades de Balanço da Bacia Hidrográfica do Rio Vaza Barris (CUNHA, 2001) e Disponibilidade e Demanda 
de Água nas Unidades de Balanço das Bacias Hidrográficas de Sergipe (CUNHA, 2002).

De base destes dados, foi realizada uma análise sobre a vulnerabilidade hídrica na porção sergipana da bacia do rio Vaza Barris utilizando os indicadores relativos ao saldo hídrico, tipo de aqüífero, precipitação pluviométrica, tipo de solo e utilização das terras, considerados como um retrato (mesmo que parcial) das condições naturais e das pressões antrópicas acerca dos recursos hídricos.

Desta forma, associando a metodologia proposta por Magalhães Júnior (2007) para os indicadores socioambientais e de recursos hídricos, foram propostos indicadores expressos em três classes tomando como referência uma escala numérica, universalmente utilizada para os indicadores ambientais. A escala varia de 0 a 1 na qual o valor 0 está correlacionado com a fraca vulnerabilidade, 0,5 com média vulnerabilidade e 1 indica uma elevada vulnerabilidade hídrica. Estes valores estão associados ao percentual de saldo hídrico da bacia, bem como ao tipo de aqüífero, volume da precipitação, grau de erodibilidade dos solos e utilização das terras. Assim, quanto maior o índice obtido por determinada unidade de planejamento maior será a vulnerabilidade hídrica

A bacia do rio Vaza Barris, objeto deste estudo, apresenta uma diversidade de aspectos socioambientais. Abrange os estados da Bahia e Sergipe (Figura 01), sendo que no primeiro apresenta grande intermitência de seus rios e baixa densidade demográfica, quando comparada ao segundo Estado. O seu baixo curso, objeto deste estudo, localiza-se em Sergipe, ocupando uma área de $2.559,0 \mathrm{~km}^{2}$.

Abrangendo 14 municípios distribuídos em 6 micro-regiões do estado, esta bacia destaca-se em termos de crescimento populacional tanto em áreas urbanas como em áreas rurais, com médias superiores à média de crescimento da população de todo o estado de Sergipe.

De acordo com a nova divisão territorial para fins de planejamento do Estado de Sergipe, a parte sergipana da bacia abrange três territórios: Agreste Central, Centro Sul e Grande Aracaju. No entanto, optou-se por uma 
regionalização da mesma em três sub-unidades, tomando como base 0 componente climático que irá influenciar fortemente a questão hídrica, objeto principal deste estudo.

Assim, os municípios que apresentam mais de $75 \%$ de seu território totalmente inseridos no Polígono das Secas, não apresentando a influência estuarina, foram considerados como integrantes do Alto-baixo curso (Simão Dias, Carira, Frei Paulo, Pedra Mole, Pinhão e Macambira). Os municípios com menos de $75 \%$ de seus territórios inseridos no Polígono das Secas e que não apresentam influência estuarina integram o Médio-baixo curso (Lagarto, São Domingos, Itabaiana, Campo do Brito e Areia Branca). Por fim, os municípios fora do Polígono das Secas e que apresentam influência estuarina estão efetivamente no Baixo curso (Itaporanga d'Ajuda, São Cristóvão e Aracaju). Esta regionalização irá permear a análise da questão hídrica na bacia (Figura 02).

Apresentado uma população total em torno de 280.000 habitantes, a bacia sergipana do rio Vaza Barris tem apresentado uma ocupação do seu espaço de forma desordenada. Um dos desdobramentos deste fator pode ser constatado nos dados relacionados com a infraestrutura, os quais demonstram que $15,9 \%$ das famílias residentes na bacia não apresentam abastecimento adequado de água e 54,5\% não possuem esgotamento sanitário adequado (SIAB, 2007).

Estes valores tornam-se preocupantes, pois se há uma tendência desta bacia em ser uma área de elevado crescimento populacional, por outro lado, não apresenta um ordenamento espacial adequado, comprometendo a qualidade de vida local e ocasionando uma maior pressão sobre os recursos naturais, e em especial sobre o recurso água, fonte de usos múltiplos na bacia.

Dentre estes usos merece destaque o abastecimento público, industrial e a irrigação, além da dessendentação de animais, pesca, turismo e lazer. Contraditoriamente o rio Vaza Barris é também utilizado como corpo receptor de efluentes domésticos, industriais e agro-industriais.

Não obstante, as políticas públicas voltadas para a gestão dos recursos hídricos nesta bacia, embora visem ordenar os múltiplos usos da água na 
tentativa de organizar sócio e espacialmente as atividades humanas neste espaço, ainda são incipientes em face da iminente problemática hídrica estadual.

\section{Indicadores de Vulnerabilidade Hídrica: o caso da bacia sergipana do rio Vaza Barris}

O clima é considerado como um dos fatores naturais que, direta ou indiretamente, influencia na degradação dos recursos naturais renováveis, pois controla os processos de intemperismo através da temperatura e das precipitações e, indiretamente, através da cobertura vegetal.

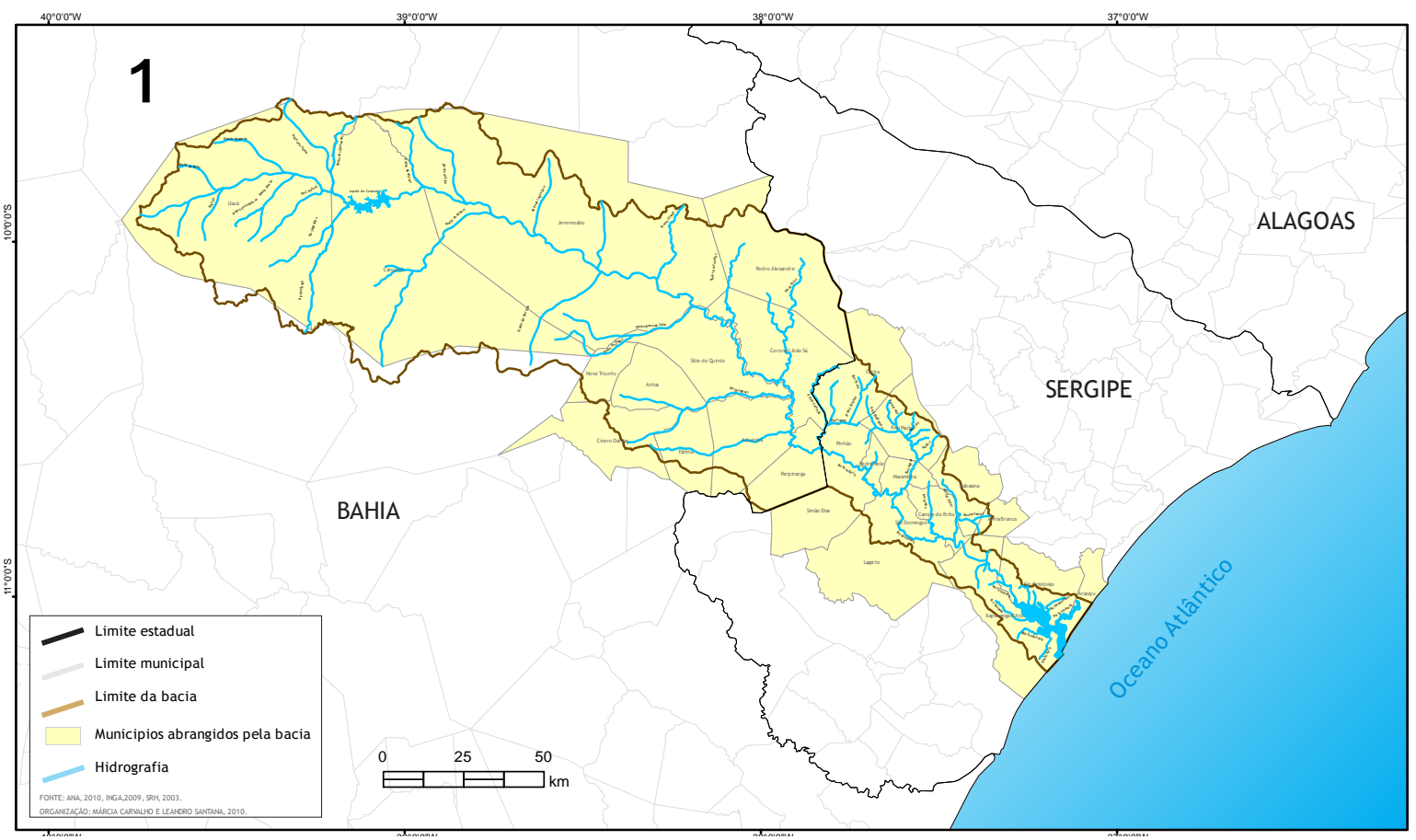

Figura 01 - Bacia do rio Vaza Barris/SE - Bahia e Sergipe 


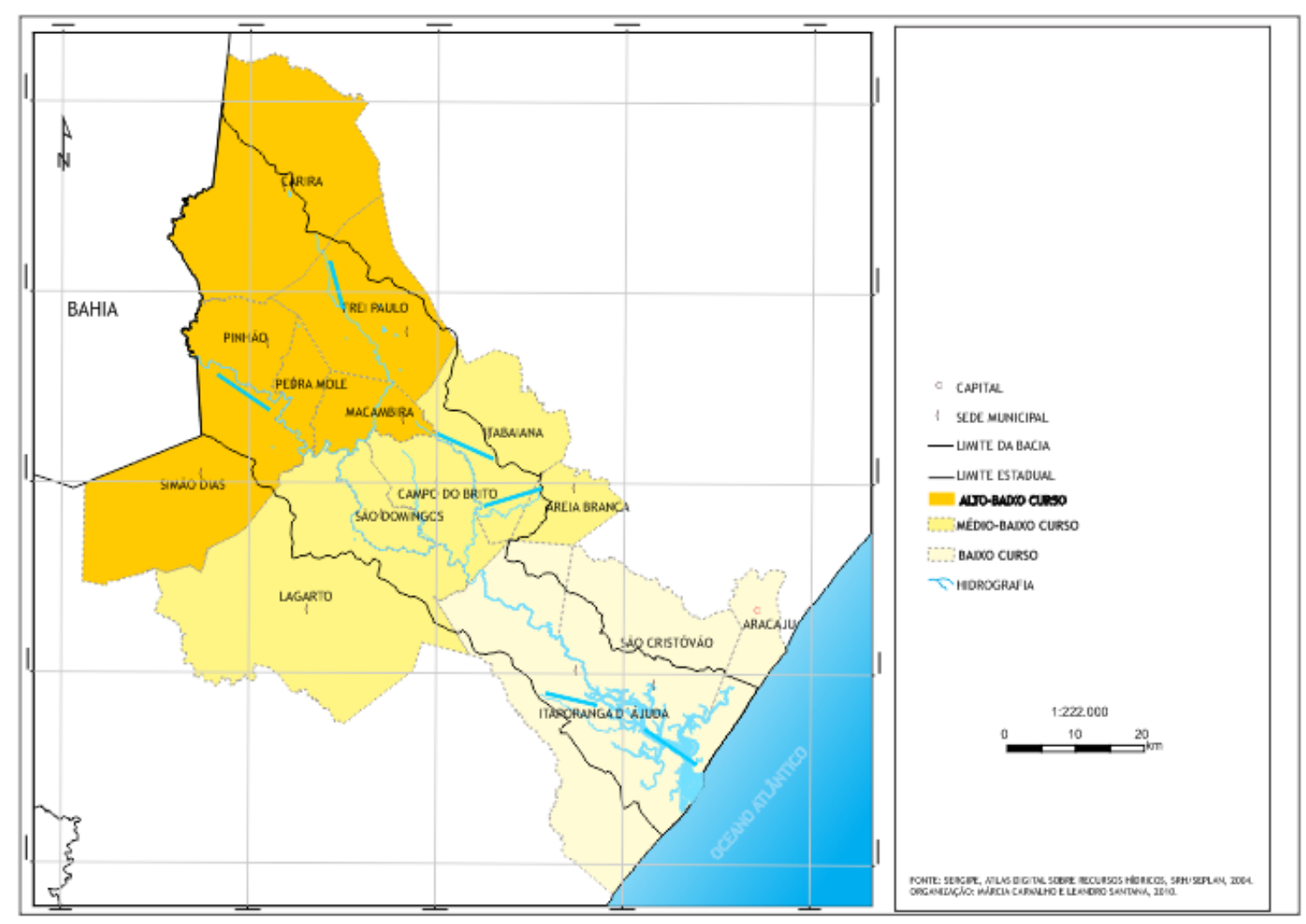

Figura 02 - Bacia do rio Vaza Barris/SE - Divisão Político-Administrativa e Regionalização Proposta

A precipitação pluviométrica é um dos fatores climáticos que mais influenciam na erosão dos solos e conseqüente assoreamento de rios, contribuindo para o aumento deste processo na medida em que a cobertura vegetal é substituída por outras atividades que impactam o solo.

Por isto, existe uma relação direta entre o tipo de uso da terra e o potencial de degradação do solo e dos corpos hídricos, sendo elevado em solos desnudos e mínimo em áreas de matas e/ou florestas. O tipo de cultivo utilizado também tem uma parcela significativa no processo erosivo, sendo mais impactante o uso do solo relacionado com as lavouras temporárias e as pastagens, caso não ocorram práticas conservacionistas do solo.

Ao mesmo tempo as condições hidrogeológicas presentes na bacia determinam as características dos aqüíferos. A água subterrânea é de fundamental importância para a manutenção da perenidade de um curso de 
água, e apresenta relação direta com o clima, tipo de solo, de rocha, declividade, cobertura vegetal, dentre outros.

Tomando como base estas considerações, os indicadores utilizados para analisar a vulnerabilidade hídrica na porção sergipana da bacia do rio Vaza Barris expressam dados relativos ao saldo hídrico, tipo de aqüífero, precipitação pluviométrica, solo e utilização das terras, considerados como um retrato (mesmo que parcial) das condições naturais e das pressões antrópicas sobre os recursos hídricos.

Devido à ausência de dados municipais detalhados sobre estes indicadores e em função da abrangência da bacia, optou-se pela análise dos mesmos para as Unidades de Balanço ou Unidade de Planejamento Hídrico, previamente definidas por um estudo realizado pela Japan International Cooperation Agency no estado de Sergipe (JICA, 2000) (Figura 03).

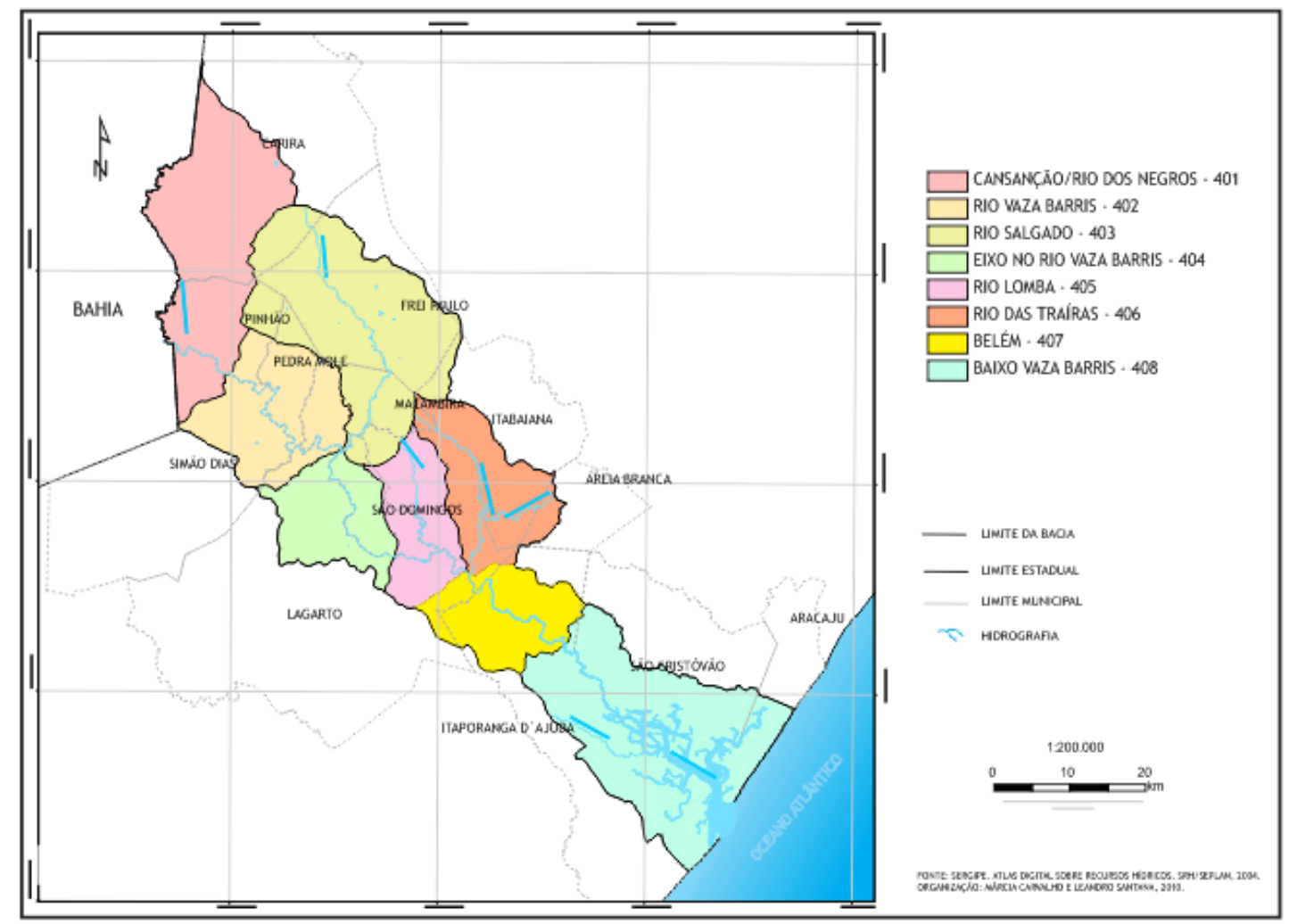

Figura 03 - Bacia do rio Vaza Barris/SE - Unidades de Planejamento. 
As unidades de balanço abrangem mais de um município. As maiores são: rio Salgado, 534,4km²; Baixo Vaza Barris, $405 \mathrm{~km}^{2}$ e Cansanção/Rio dos Negros, $447,5 \mathrm{~km}^{2}$. As menores são Eixo no Vaza Barris, Belém e Rio Vaza Barris, com 193, 281 e $281,1 \mathrm{~km}^{2}$, respectivamente (Quadro 1).

Quadro 1 - Localização e área total das Unidades de Planejamento na bacia do rio Vaza Barris/SE.

\begin{tabular}{|c|c|c|}
\hline $\begin{array}{r}\text { Unidades de } \\
\text { Planejamento / UBH }\end{array}$ & Municípios & $\begin{array}{l}\text { Área } \\
\left(\mathrm{km}^{2}\right)\end{array}$ \\
\hline 401 - Cansanção/Rio dos Negros & $\begin{array}{c}\text { Carira e parcialmente Pinhão e Simão } \\
\text { Dias }\end{array}$ & 447,5 \\
\hline 402 - Rio Vaza Barris & $\begin{array}{l}\text { Abrange parcialmente Simão Dias, } \\
\text { Pinhão, Pedra Mole e Lagarto }\end{array}$ & 281,1 \\
\hline 403 - Rio Salgado & $\begin{array}{c}\text { Frei Paulo, Macambira e } \\
\text { parcialmente Pinhão, Pedra Mole, Campo } \\
\text { do Brito e Lagarto }\end{array}$ & 534,2 \\
\hline 404 - Eixo no Rio Vaza Barris & $\begin{array}{l}\text { Abrange parcialmente Lagarto e } \\
\text { São Domingos }\end{array}$ & 193,0 \\
\hline 405 - Rio Lomba & $\begin{array}{l}\text { Campo do Brito e parcialmente } \\
\text { São Domingos e Itaporanga d'Ajuda }\end{array}$ & 178,5 \\
\hline 406 - Rio das Traíras & $\begin{array}{l}\text { Itabaiana, Areia Branca e parte de } \\
\text { Campo do Brito }\end{array}$ & 240,3 \\
\hline 407 - Belém & $\begin{array}{l}\text { Zona rural de parte de Itaporanga } \\
\text { e São Cristóvão }\end{array}$ & 281,0 \\
\hline 408 - Baixo Vaza Barris & $\begin{array}{c}\text { Abrange parcialmente Itaporanga, } \\
\text { São Cristóvão e a Zona de Expansão de } \\
\text { Aracaju }\end{array}$ & 405,0 \\
\hline \multicolumn{2}{|r|}{ TOTAL } & $2.560,6$ \\
\hline
\end{tabular}

Fonte: JICA (2000).

Em 2000, a população da bacia totalizava 221.868 habitantes, o que correspondia a uma densidade demográfica de $86,64 \mathrm{hab} / \mathrm{km}^{2}$. A população rural era superior à urbana, totalizando 52,7\%, concentrada principalmente nas unidades Rio Salgado (57.390 habitantes), Rio das Traíras (11.579) e Belém (4.970). A população urbana abrangia $47,3 \%$ do total da população da bacia, sendo que a unidade que concentra um maior contingente urbano é a o do Baixo Vaza Barris com 72.073 habitantes (Tabela 1).

O cenário prospectivo para 2025 demonstra que a população crescerá em torno de 52,5\% e a densidade da bacia ficará em torno de $132,2 \mathrm{hab} / \mathrm{km}^{2}$. A população urbana será superior à rural $(58,7 \%$ e $41,3 \%$, respectivamente). A 
densidade demográfica atingirá valores elevados principalmente no Baixo Vaza Barris $\left(341,2 \mathrm{hab} / \mathrm{km}^{2}\right)$, Rio Salgado $\left(231,1 \mathrm{hab} / \mathrm{km}^{2}\right)$ e Rio Lomba $(102,1$ $\left.\mathrm{hab} / \mathrm{km}^{2}\right)$ (CUNHA, 2001).

Tabela 1 - População urbana, rural e total nas Unidades de Balanço Hídrico da Bacia do rio Vaza Barris em Sergipe (2000).

\begin{tabular}{l|l|l|l|l|l|l|l}
\hline \multirow{2}{*}{ UBH } & \multicolumn{6}{c}{ POPULAÇÃO (HAB) - 2000 } \\
\cline { 2 - 7 } & \multicolumn{2}{c|}{ Urbana } & \multicolumn{3}{c}{ Rural } & Total & DD $^{*}$ \\
\cline { 2 - 7 } & Total & $\%$ & Total & $\%$ & & \\
\hline 401 - Cansanção/Rio dos Negros & 9.446 & 9,4 & 9.680 & 0,6 & 19.126 & 42,7 \\
\hline 402 - Rio Vaza Barris & 1.100 & 12,0 & 8.056 & & 9.156 & 3,5 \\
& & & & 8,0 & & \\
\hline 403 - Rio Salgado & 11.609 & 16,8 & 57.390 & & 68.999 & 29,1 \\
& & & & 3,2 & & \\
\hline 404 - Eixo no Rio Vaza Barris & 3.913 & 30,1 & 9.057 & 9,9 & 12.970 & 7,2 \\
\hline 405 - Rio Lomba & 6.556 & 45,7 & 7.801 & 4,3 & 14.357 & 0,4 \\
\hline 406 - Rio das Traíras & 345 & 2,9 & 11.579 & 7,1 & 11.924 & 9,6 \\
\hline 407 - Belém & 0 & 0,0 & 4.970 & 00,0 & 4.970 & 7,7 \\
\hline 408 - Baixo Vaza Barris & 72.073 & 89,7 & 8.291 & 0,3 & 80.364 & 98,4 \\
\hline \multicolumn{1}{c}{ Total } & 105.042 & 47,3 & 116.826 & 2,7 & 221.868 & 6,64 \\
\hline
\end{tabular}

* Densidade Demográfica.

Fonte: Cunha (2001).

Desta forma, somente este setor de usuários dos recursos hídricos, representará uma pressão cinqüenta vezes a mais que a atual. Caso os usos das águas continuem de forma não planejada refletirá numa séria problemática hídrica para a bacia.

Em termos hidrogeológicos foram identificados na bacia em estudo os seguintes domínios: Formações Superficiais Cenozóicas, Bacias Sedimentares, Grupo Estância, Metacarbonatos, Metasedimentos/Metavulcanitos e Cristalino (Figura 04).

O aqüífero do tipo granular é mais abrangente na porção costeira da bacia, apresentando alta porosidade e permeabilidade que se traduz em aqüíferos com boas reservas hídricas. $O$ do tipo fissural e fissural muito fraturado, ambos predominando na porção mais interiorana da bacia, são compostos por rochas que apresentam de baixa a muito baixa porosidade conferindo uma reserva hídrica menor e descontínua. 


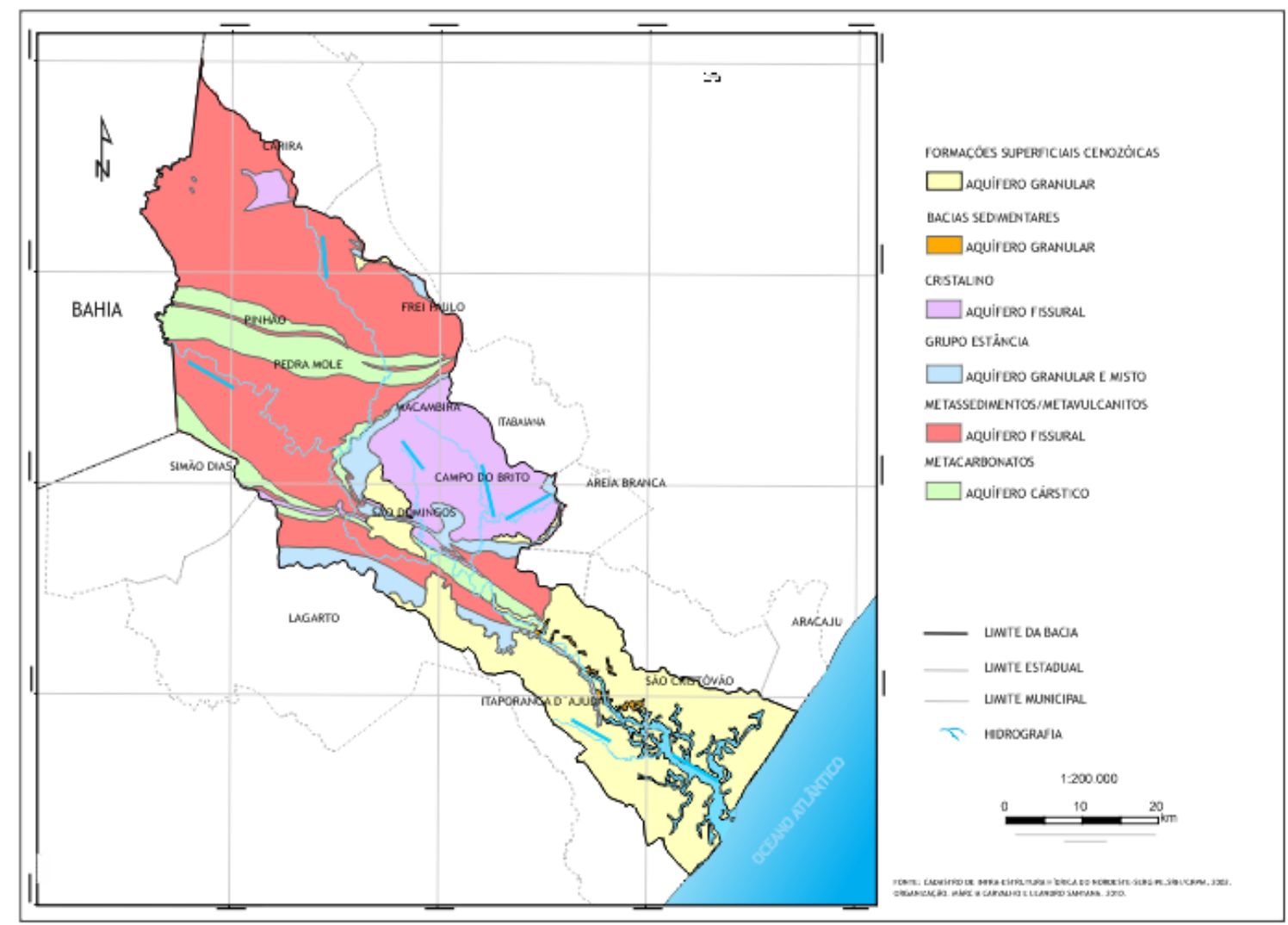

Figura 04 - Bacia do rio Vaza Barris/SE - Domínios Hidrogeológicos.

Em estudo realizado por Pinto (1997) sobre a pluviosidade no estado Sergipe, foi possível classificar os municípios sergipanos em função das variações na precipitação: Sertão - municípios cuja precipitação média anual varia de 450 a $850 \mathrm{~mm}$; Agreste - as variações entre 850 e $1.200 \mathrm{~mm}$; e Zona da Mata - variação entre 1.200 e $1.500 \mathrm{~mm}$.

Tomando como base esta classificação, aproximadamente $78 \%$ dos municípios integrantes da bacia estão localizados no agreste sergipano, sendo que Simão Dias, Lagarto e Frei Paulo estão parcialmente inseridos no Sertão.

Com relação à pluviosidade, os municípios de Carira, Pinhão, Pedra Mole, Frei Paulo e Macambira apresentam as menores pluviosidades da bacia, de 800 a $1000 \mathrm{~mm}$ anuais, enquanto que Aracaju, São Cristóvão e Itaporanga d'Ajuda apresentam valores acima de $1.300 \mathrm{~mm}$ anuais (Figura 05). 


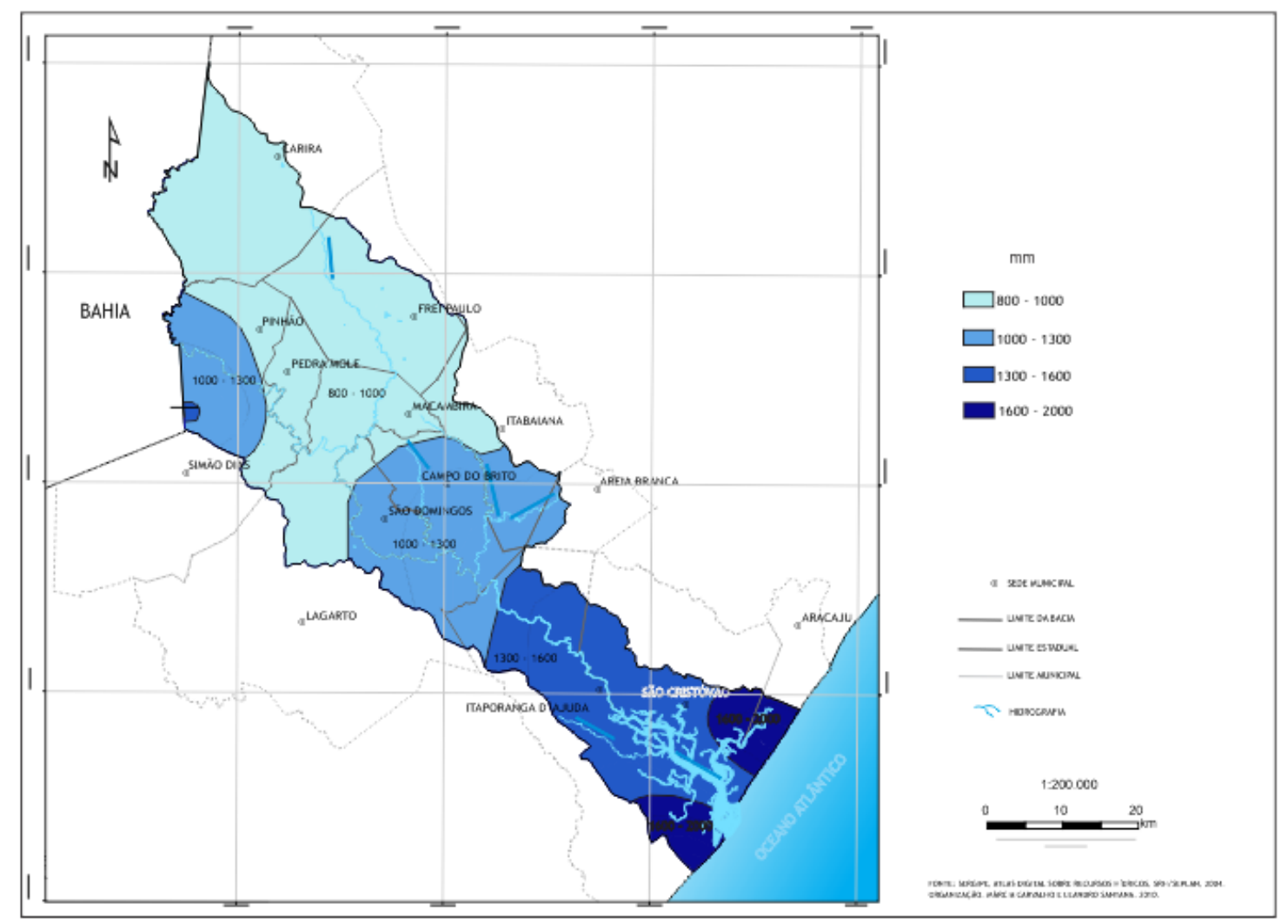

Figura 05 - Bacia do rio Vaza Barris/SE - Precipitação.

De estreita relação com o potencial erosivo do solo encontra-se o uso da terra. Existe uma relação direta entre o tipo de uso da terra e o potencial de degradação do solo e conseqüentemente dos corpos hídricos adjacentes, sendo elevado nas lavouras temporárias, reduzindo com as permanentes e mínimo com as matas e/ou florestas.

As pastagens predominam no Vaza Barris Sergipano, totalizando 196.099ha (63,6\% da área agricultável da bacia) dos quais, 59,5\% são do tipo plantada, geralmente com forrageiras, e $40,5 \%$ são naturais nas quais o gado pasta sem haver o plantio prévio da vegetação. As lavouras somam $77.000 \mathrm{ha}$ ( $25 \%$ da área agricultável da bacia) das quais $57,4 \%$ são temporárias (que apresentam ciclo curto de colheita), 21,8\% são caracterizadas como outros usos e $20,8 \%$ caracterizam as lavouras permanentes (cultivos duradouros). As matas totalizam apenas $6,6 \%$, os sistemas agroflorestais, $1,8 \%$ e as áreas não ocupadas com as especificações anteriores somam 2,9\% (IBGE, 2006) 
A maioria dos municípios integrantes da bacia apresenta-se fortemente vinculado à pecuária, pois ao ser somada a área total destinada à lavoura e à pastagem obtêm-se um índice superior a $60 \%$ da área municipal destinada às pastagens, destacando-se Macambira (87\%), Lagarto (80\%), Carira $(77,5 \%)$, Itaporanga d'Ajuda (72,2\%), Pedra Mole (70,6\%) e Campo do Brito (70\%). A orientação do meio rural para a produção agrícola de hortifruti é evidenciada apenas em Areia Branca (54,0\%) e Itabaiana (44,3\%).

Este vínculo com a pecuária é o reflexo do processo de ocupação do espaço interiorano do estado, associado às condições ambientais, e embora se faça presente em todos os extratos de área, é considerada como uma importante alternativa econômica para o agricultor.

A partir da integração destes dados, os indicadores foram classificados em três classes tomando como referência uma escala numérica, universalmente utilizada para os indicadores ambientais, associando a metodologia proposta por Magalhães Júnior (2007) para os indicadores socioambientais e de recursos hídricos.

Vale ressaltar que a escolha dos indicadores e as escalas utilizadas irão variar de acordo com o grau de subjetividade do pesquisador, bem como dos objetivos da pesquisa.

Assim, neste trabalho foi utilizada uma escala que variou de 0 a 1 na qual o valor 0 está correlacionado com a fraca vulnerabilidade, 0,5 com média vulnerabilidade e 1 indica uma elevada vulnerabilidade hídrica. Estes valores estão associados ao percentual de saldo hídrico da bacia, bem como ao tipo de aqüífero, volume da precipitação, grau de erodibilidade dos solos e utilização das terras. Assim, quanto maior o índice obtido por determinada unidade de planejamento maior será a vulnerabilidade hídrica (Quadro 2).

Para identificação do saldo hídrico foram utilizados os dados do cenário prospectivo para 2010 constantes em Cunha (2002) que elaborou um estudo sobre a disponibilidade e demanda de água nas unidades de balanço das bacias hidrográficas de Sergipe, devendo também ser consideradas as ressalvas relativas a estas unidades que não englobam todo o município. Quando o saldo hídrico nas unidades de planejamento é maior que $60 \%$, indica 
uma vulnerabilidade fraca, pois significa que as demandas na unidade de planejamento não chegam a $50 \%$ das disponibilidades existentes, não exercendo, dessa forma, pressões elevadas sobre as águas. Entre 60 e 20\% a vulnerabilidade é considerada Média e menor que $20 \%$ indica um saldo hídrico já no limite das disponibilidades para a realidade da bacia.

Quadro 2 - Indicadores para diagnóstico de Vulnerabilidade Hídrica.

\begin{tabular}{|c|c|c|c|c|}
\hline \multicolumn{5}{|c|}{ Grau de Vulnerabilidade Hídrica } \\
\hline Indicadores & $\begin{array}{c}\text { Base dos } \\
\text { dados }\end{array}$ & $\begin{array}{c}\text { Fraca } \\
(0)\end{array}$ & $\begin{array}{c}\text { Média } \\
(0,5)\end{array}$ & $\begin{array}{l}\text { Alta } \\
(1)\end{array}$ \\
\hline Saldo Hídrico & $\begin{array}{l}\text { CUNHA } \\
(2002)\end{array}$ & $>60 \%$ & 60 a $20 \%$ & $<20 \%$ \\
\hline $\begin{array}{l}\text { Tipo de } \\
\text { Aqüífero }\end{array}$ & CPRM (2002) & $\begin{array}{c}\text { Predominância } \\
\text { do aqüífero do } \\
\text { tipo Granular }\end{array}$ & $\begin{array}{c}\text { Coexistências } \\
\text { do tipo Fissural } \\
\text { ou do tipo } \\
\text { Granular/Misto }\end{array}$ & $\begin{array}{l}\text { Predominância do } \\
\text { aqüífero do tipo } \\
\text { Fissural e/ou } \\
\text { cárstico }\end{array}$ \\
\hline $\begin{array}{l}\text { Precipitação } \\
\text { Pluviométrica }\end{array}$ & $\begin{array}{l}\text { SRH (2004), } \\
\text { PINTO (1997) }\end{array}$ & $\begin{array}{c}>1.300 \mathrm{~mm} \\
\text { anuais }\end{array}$ & $\begin{array}{c}1.000 \text { a } 1.300 \\
\mathrm{~mm} \text { anuais }\end{array}$ & $\begin{array}{c}<\text { que } 1.000 \mathrm{~mm} \\
\text { anuais }\end{array}$ \\
\hline $\begin{array}{l}\text { Tipo de solo } \\
\text { associados ao } \\
\text { Grau de } \\
\text { Susceptibilidade } \\
\text { à erosão }\end{array}$ & $\begin{array}{l}\text { IBGE (2007), } \\
\text { ROSS (1994) }\end{array}$ & Latossolos & $\begin{array}{l}\text { Planossolos e } \\
\text { Argissolos }\end{array}$ & $\begin{array}{l}\text { Neossolos } \\
\text { Litólicos e } \\
\text { Cambissolos }\end{array}$ \\
\hline $\begin{array}{l}\text { Utilização das } \\
\text { terras }\end{array}$ & IBGE (2006) & $\begin{array}{l}\text { Predomínio de } \\
\text { lavouras } \\
\text { permanentes e } \\
\text { pastagens } \\
\text { plantadas }\end{array}$ & $\begin{array}{l}\text { Pastagens } \\
\text { natural e } \\
\text { lavouras } \\
\text { temporárias } \\
\text { com área } \\
\text { menor do que } \\
60 \% \text { do total } \\
\text { municipal }\end{array}$ & $\begin{array}{l}\text { Pastagens natural } \\
\text { e lavouras } \\
\text { temporárias com } \\
\text { área maior do que } \\
60 \% \text { do total } \\
\text { municipal }\end{array}$ \\
\hline
\end{tabular}

Em termos hidrogeológicos, o aquífero do tipo fissural foi classificado como de Alta vulnerabilidade, pois apresenta reservatórios aleatórios, descontínuos, de pequena extensão e vazão, muitas vezes salinizados devidos às condições geológicas dominantes, sendo pouco utilizados como fonte alternativa predominante para abastecimento humano. $\mathrm{O}$ aqüífero cárstico também integra esta classe, pois a água é do tipo carbonatada com limitações para uso humano. Com Média vulnerabilidade foram classificadas as unidades que apresentam vários tipos de aqǘferos, sendo que não há predominância do 
tipo granular. As unidades que apresentam aqüífero do tipo granular apresentam Baixa vulnerabilidade, pois a elevada permeabilidade da estrutura geológica que o compõe confere boas condições de armazenamento e descarga hídrica, podendo ser utilizados para abastecimento humano.

Vale ainda ressaltar que o uso da água subterrânea ocorre em todos os municípios da bacia. A principal finalidade está enquadrada como uso múltiplo $(67,4 \%)$, podendo ainda ser identificadas as categorias de uso doméstico, agrícola e dessendentação animal evidenciando a importância os recursos hídricos subterrâneos para as atividades humanas.

Sobre os aspectos qualitativos destaca-se um elevado índice de poços que não possuem análise de parâmetros químicos e biológicos, ressaltando a necessidade de ações integradas de gestão hídrica, visando compatibilizar as potencialidades do aqüífero com os múltiplos usos, bem como para diagnosticar o grau de interferência antrópica no referido ponto de captação.

Do total de 1886 poços cadastrado até 2002, 40\% não apresentam uma caracterização da qualidade da água (CPRM, 2002). Os municípios que mais carecem de informação sobre tipo de uso e qualidade da água são Carira (70,2\%), Frei Paulo (70,6\%), Pinhão (62,0\%), Macambira (53,3\%), Simão Dias $(50,6 \%)$ e Areia Branca $(50,9 \%)$.

Os cinco primeiros integram o Alto-baixo curso da bacia, apresentando clima de transição para o semi-árido, estão totalmente inseridos no Polígono das Secas e apresentam elevada intermitência de seus rios. Ou seja, reúnem características que conferem a necessidade de aumento da oferta hídrica e de uma avaliação constante da qualidade das suas águas subterrâneas, sendo que a realidade exprime justamente o contrário. Em Carira, Frei Paulo, Pedra Mole e Simão Dias além da ausência de dados qualitativos, o total de poços paralisados, não instaladas ou abandonados superam $50 \%$ do total.

As unidades com baixas pluviosidades mal distribuídas ao longo do ano, associadas ao clima mais próximo da região árida foram caracterizadas como de Alta vulnerabilidade; pluviosidade variando de 1.000 a $1.300 \mathrm{~mm}$, característico do agreste sergipano, foi classificada como de Média 
vulnerabilidade, sendo a Baixa vulnerabilidade característica de um clima mais úmido com chuvas bem distribuídas ao longo do ano.

Devido à escala do mapeamento dos solos disponível (1:200.000), não foi possível obter um nível maior de detalhes, sendo que os solos foram classificados em apenas 3 classes de susceptibilidade a erosão - Baixa, Média e Alta. Para tal foram utilizadas informações sobre as características pedológicas dos mesmos, no tipo de uso a que são submetidos, associando ainda com o grau de fragilidade dos solos proposto por Ross (1994).

Esta classificação tomou como base os principais tipos de solos da bacia: Neossolo Litólico, que predomina no Alto-baixo curso e em parte do Médio-baixo curso; Planossolo de ocorrência no Médio-baixo curso e o Argissolo predominante no Baixo curso. Ocorrem ainda secundariamente 0 Cambissolo no Alto-baixo curso e o Latossolo no Baixo curso (Figura 06).

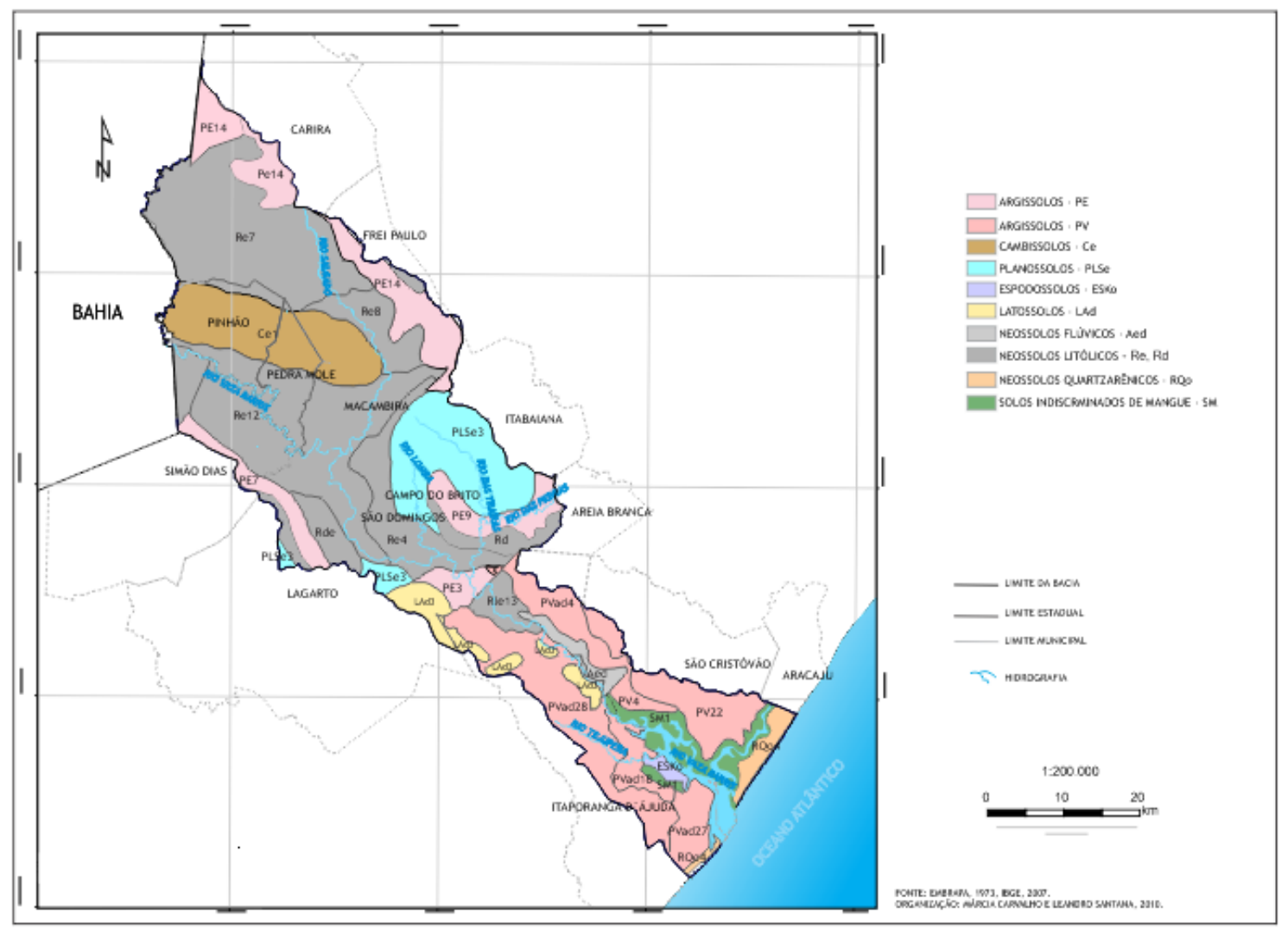

Figura 06 - Bacia do rio Vaza Barris/SE - Solos. 
Desta forma, o Neossolo Litólico e o Cambissolo foram considerados como de Alta susceptibilidade à erosão em função de serem solos rasos, pouco desenvolvidos e, especialmente o primeiro, apresenta elevada pedregosidade sendo submetidos a um uso intenso na pecuária com pastagens do tipo natural, sem haver descanso do solo. Na classificação proposta por Ross (1994) eles integram a classe de fragilidade denominada de Muito Forte.

O Planossolo foi classificado como de Média susceptibilidade a erosão por não ser pedregoso e por apresentar relativa profundidade. Ocorre em áreas de relevo plano ou suave ondulado e voltado para cultivos temporários, o que pode gerar degradação do mesmo. Em comparação com o Neossolo e o Cambissolo, pode ser melhor utilizado com os cultivos agrícolas, desde que haja manejo adequado para manutenção da fertilidade e redução da erodibilidade. Esta classe não foi contemplada na proposta de Ross (op cit.).

O Argissolo também foi classificado como de Média Fragilidade, conforme classificação proposta de Ross (op.cit.), mas vale destacar que para a área em estudo, baseando-se nas considerações de Mendonça Filho (2000), estes solos são férteis, apresentando maior eficiência quando sobre os mesmos são estabelecidos cultivos de espécies perenes que não necessitam de revolvimento anual contribuído para reduzir as perdas por erosão, uma vez que reduz o impacto das gotículas de chuva diretamente sobre o solo. Estas considerações são pertinentes à bacia, pois na unidade onde ocorrem predominam cultivos permanentes associado a precipitações bem distribuídas ao longo do ano com relevo do tipo suave a suavemente ondulado.

A articulação destas informações permite analisar que as unidades de planejamento / balanço hídrico 401, 402, 403 e 404, descritas no quadro 1 e tabela 1, apresentam limitações naturais relativas ao tipo de aqüífero, pois há predominância do fissural; precipitação, que são as mais baixas de toda a bacia; tipo de solo, o qual predomina o Neossolo Litólico, com todas as fragilidades expostas anteriormente, bem como um uso intensivo do solo (Tabela 2). 
Tabela 2 - Dados brutos para avaliação da vulnerabilidade hídrica na bacia sergipana do rio Vaza Barris.

\begin{tabular}{|c|c|c|c|c|c|}
\hline $\begin{array}{l}\text { Unidades de } \\
\text { Planejamento }\end{array}$ & $\begin{array}{c}\text { Saldo } \\
\text { Hídrico } \\
(\%)\end{array}$ & $\begin{array}{c}\text { Tipo de } \\
\text { Aqüífero } \\
\text { predominante }\end{array}$ & $\begin{array}{c}\text { Precipitação } \\
\text { (mm/ano) }\end{array}$ & $\begin{array}{l}\text { Tipo de solo } \\
\text { predominante }\end{array}$ & $\begin{array}{c}\text { Uso da } \\
\text { terra }\end{array}$ \\
\hline 401 & 85 & Fissural & $800-1000$ & $\begin{array}{l}\text { Neossolo } \\
\text { Litólico }\end{array}$ & $\begin{array}{l}\text { P.N. e } \\
\text { L.T. > } \\
60 \% \text { * }\end{array}$ \\
\hline 402 & 93,6 & Fissural & $800-1000$ & $\begin{array}{l}\text { Neossolo } \\
\text { Litólico }\end{array}$ & $\begin{array}{l}\text { P.N. e } \\
\text { L.T. > } \\
60 \% \text { * }\end{array}$ \\
\hline 403 & 54,3 & Fissural & $800-1000$ & $\begin{array}{c}\text { Neossolo } \\
\text { Litólico e } \\
\text { Cambissolo }\end{array}$ & $\begin{array}{l}\text { P.N. e } \\
\text { L.T. > } \\
60 \% \text { * }\end{array}$ \\
\hline 404 & 88,8 & Fissural & $800-1000$ & $\begin{array}{l}\text { Neossolo } \\
\text { Litólico }\end{array}$ & $\begin{array}{l}\text { P.N. e } \\
\text { L.T. > } \\
60 \% \text { * }\end{array}$ \\
\hline 405 & $-2,65$ & $\begin{array}{l}\text { Granular/Misto } \\
\text { Fissural }\end{array}$ & $\begin{array}{l}1.000- \\
1.3000\end{array}$ & Planossolo & $\begin{array}{l}\text { P.N. e } \\
\text { L.T. > } \\
60 \% \text { * }\end{array}$ \\
\hline 406 & $-93,7$ & Fissural & $\begin{array}{l}1.000- \\
1.3000\end{array}$ & Planossolo & $\begin{array}{l}\text { P.N. e } \\
\text { L.T. < } \\
60 \% \text { ** }\end{array}$ \\
\hline 407 & 98,8 & $\begin{array}{l}\text { Granular e } \\
\text { Fissural }\end{array}$ & $>1.300$ & Argissolo & $\begin{array}{l}\text { P.N. e } \\
\text { L.T.*** }\end{array}$ \\
\hline 408 & 76,3 & Granular & $>1.300$ & Argissolo & $\begin{array}{l}\text { P.N. e } \\
\text { L.T. }{ }^{* * *}\end{array}$ \\
\hline
\end{tabular}

* Pastagens natural e lavouras temporárias com área maior do que $60 \%$ do total municipal.

** Pastagens natural e lavouras temporárias com área menor do que $60 \%$ do total municipal.

*** Predomínio de lavouras permanentes e pastagens plantadas.

As unidades 405 e 406, embora apresentem menor severidade com relação às precipitações e erodibilidade dos solos, apresentam como maior fator limitante o saldo hídrico negativo, ou seja, déficit hídrico principalmente relacionado com o Perímetro Irrigado da Ribeira, localizado no município de Itabaiana e que apresenta uma área irrigável de 1.100 ha. Por outro lado, o Baixo curso (municípios de Aracaju, Itaporanga d' Ajuda e São Cristóvão que recebem a influência estuarina) apresenta as menores limitações ambientais denotando uma menor vulnerabilidade, embora não signifique que os 
processos degradantes pelo uso desordenado do solo e pelo processo acelerado de urbanização não comprometam a qualidade hídrica local.

A articulação destes indicadores apresenta o perfil da bacia em termos de Vulnerabilidade Hídrica. A avaliação final determinou o Índice de Vulnerabilidade constituído por valores entre 0 e 1 , obtido dividindo a soma total de cada unidade de planejamento pelo valor máximo que uma poderia obter, no caso 5 pontos, obedecendo a seguinte escala: Vulnerabilidade Alta valores acima de 0,8, que retrata elevada fragilidade natural e intensa pressão antrópica sobre os recursos hídricos; Vulnerabilidade Média entre 0,4 a 0,79, que aponta um uso intenso das águas; e Vulnerabilidade Baixa - abaixo de 0,39 , nas quais as condições ambientais analisadas não exercem pressão elevada sobre as disponibilidades hídricas. Desta forma, quanto maior o valor obtido maior a Vulnerabilidade Hídrica na unidade de planejamento.

Assim, a Vulnerabilidade hídrica Alta foi identificada nas unidades 401, 402, 403 e 404, pertencentes em sua maior parte ao Alto-baixo curso, englobando os municípios de Carira, Frei Paulo, Pedra Mole, Pinhão, Simão Dias, Macambira e Lagarto. O valor total mais elevado foi identificado na unidade 403 que engloba a sub-bacia do rio Salgado, maior unidade dentro da bacia. $O$ índice de Vulnerabilidade média foi diagnosticado para as unidades 405 e 406, que abrangem os municípios de Campo do Brito, Itabaiana e Areia Branca, localizados no Médio-baixo curso. Os menores valores foram encontrados para o Baixo curso da bacia, municípios de Itaporanga d'Ajuda, São Cristóvão e a Zona de Expansão de Aracaju (Tabela 3 e Figura 6).

Neste último caso há a articulação de aqüíferos com maior e melhor capacidade de armazenamento, maior saldo em termos de precipitação ao longo do ano associado a uma média erodibilidade dos solos.

O saldo hídrico não foi fator limitante, mas deve-se levar em consideração as ponderações realizadas no item anterior, sendo que a totalidade do município poderá levar sim a um déficit hídrico, pois muitas vezes não é possível dividir o município ao meio para ofertar água de uma bacia para um lado e de outra bacia para o outro. A unidade municipal apresenta, então, 
forte significado neste processo e deveria ser considerada em estudos técnicos posteriores sobre disponibilidade e demandas hídricas.

Tabela 3 - Vulnerabilidade Hídrica na bacia do rio Vaza Barris/SE.

\begin{tabular}{c|c|c|c|c|c|c|c|c}
\hline $\begin{array}{c}\text { Unidades } \\
\text { de } \\
\text { Planeja- } \\
\text { mento }\end{array}$ & $\begin{array}{c}\text { Saldo } \\
\text { Hídrico }\end{array}$ & $\begin{array}{c}\text { Tipo de } \\
\text { Aqǘfero }\end{array}$ & Precipitação & $\begin{array}{c}\text { Erodibilidade } \\
\text { do solo }\end{array}$ & $\begin{array}{c}\text { Uso da } \\
\text { terra }\end{array}$ & \multicolumn{2}{|c|}{ Total } & \multicolumn{2}{|c|}{$\begin{array}{c}\text { Vulice de } \\
\text { dade }\end{array}$} \\
\hline $\mathbf{4 0 1}$ & 0 & 1 & 1 & 1 & 1 & 4 & 0,8 & Alta \\
\hline $\mathbf{4 0 2}$ & 0 & 1 & 1 & 1 & 1 & 4 & 0,8 & Alta \\
\hline $\mathbf{4 0 3}$ & 0,5 & 1 & 1 & 1 & 1 & 4,5 & 0,9 & Alta \\
\hline $\mathbf{4 0 4}$ & 0 & 1 & 1 & 1 & 1 & 4,0 & 0,8 & Alta \\
\hline $\mathbf{4 0 5}$ & 1 & 0,5 & 0,5 & 0,5 & 1 & 3,5 & 0,7 & Média \\
\hline $\mathbf{4 0 6}$ & 1 & 1 & 0,5 & 0,5 & 0,5 & 3,5 & 0,7 & Média \\
\hline $\mathbf{4 0 7}$ & 0 & 0,5 & 0 & 0,5 & 0 & 1,0 & 0,2 & Baixa \\
\hline $\mathbf{4 0 8}$ & 0 & 0 & 0 & 0,5 & 0 & 0,5 & 0,1 & Baixa \\
\hline
\end{tabular}

Grau de Vulnerabilidade: Fraca - 0; Média - 0,5; Alta - 1,0

Índice de Vulnerabilidade: Baixa: 0 -0,39: Média: 0,4-0,79; Alta: 0,8 - 1,0.

Estas áreas ambientalmente vulneráveis podem ser agravadas por processos de expansão urbana desordenada que trazem em seu bojo acesso limitado a saúde, educação, sistema de saneamento eficiente e que podem repercutir sobre vulnerabilidades sociais, criando, conforme apontam Garcias e Sanches (2009) vulnerabilidades socioambientais.

Associados a estes dados, os estudos sobre população demonstram que comunidades com menos recursos e com menor índice de escolaridade, associados a um baixo rendimento salarial, geralmente ocupam áreas mais periféricas com baixa qualidade nos serviços de saneamento e saúde, constituindo-se em comunidades mais vulneráveis do ponto de vista social.

Segundo Marengo (2008), a persistência da vulnerabilidade hídrica nas comunidades rurais do semi-árido brasileiro tem seu fator agravado pelas limitações econômicas e sociais. O clima no semi-árido é fator preponderante na disponibilidade hídrica, mas os aspectos de cunho econômico-social agravam a situação de vulnerabilidade local. 


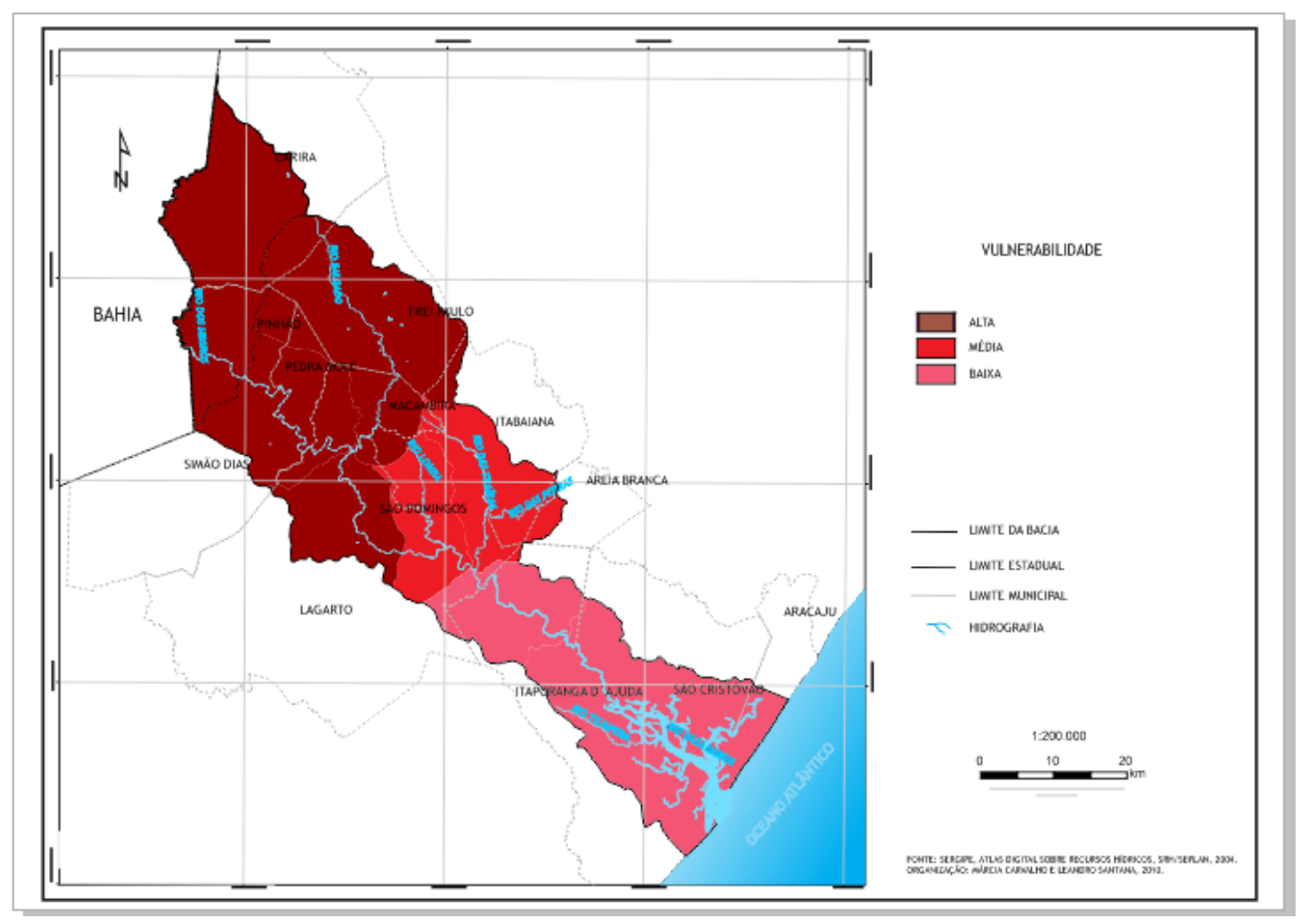

Figura 07 - Bacia do rio Vaza Barris/SE - Vulnerabilidade.

$\mathrm{Na}$ bacia sergipana do rio Vaza Barris, os dados sociais alertam para a associação íntima entre vulnerabilidade hídrica e vulnerabilidade social, esta sendo compreendida como sendo a privação da população a certos serviços públicos e ampliam a noção de risco que passam quando da ocorrência de agravos ambientais.

De acordo com Confalonieri (2003, p.193), "o conceito de vulnerabilidade social de uma população tem sido utilizado para a caracterização de grupos sociais que são mais afetados por estress de natureza ambiental" e que apresentam menor resistência de superá-los por serem excluídos social e economicamente.

Tomando como base o Alto-baixo curso da bacia, cuja vulnerabilidade hídrica é elevada, os dados de cunho social apontam para uma maior vulnerabilidade social, pois a taxa de analfabetismo na bacia, mesmo tendo 
sido reduzida entre 1991 e 2000, de 52,4\% para 40\%, ainda é elevada, superando os 40\% nos municípios de Carira, Frei Paulo, Pedra Molde, Pinhão Simão Dias e Macambira. As menores taxas encontram-se em Aracaju $(11,6 \%)$ e São Cristóvão (21,5\%), pertencentes ao Baixo curso e que usufruem de melhor distribuição de bens e serviços (PNUD, 2000).

Ao se analisar o índice de escolaridade dos responsáveis pelos domicílios na bacia constata-se que 65,5\% não completaram o ensino fundamental de nove anos (IBGE, 2000). Ocorre um elevado percentual de responsáveis pelos domicílios que não apresentam instrução ou apresentam menos de 1 ano de instrução, a exemplo de Pedra Mole (49,9\%), Carira $(46,2 \%)$, São Domingos (45,5\%), Simão Dias (45,2\%), Pinhão $(43,1 \%)$ e Campo do Brito (43,5\%). Ou seja, quase a metade dos responsáveis por domicílios da população destes municípios apresenta pouca instrução, demonstrando que o acesso aos estudos é deficitário. Embora os dados analisados refiram-se ao ano de 2000, acredita-se que a estrutura descrita tenha sido pouco modificada.

À medida que avança a escolaridade os índices ainda são mais alarmantes, pois indicam uma média de 3,0 a apenas 6,0\% dos responsáveis pelos domicílios completaram o ensino médio, sendo o menor percentual identificado em São Domingos (2,0\%). Mais uma vez Aracaju apresenta melhor situação com percentual de 24,1\%.

Quando se avalia o percentual para mais de 15 anos de estudo a situação ainda é mais precária não totalizando 1\% nos municípios analisados, exceto em São Cristóvão (1,5\%). Este fato está relacionado, dentre outros aspectos, com a interrupção dos estudos em função da necessidade de dedicação ao trabalho para sustento da família e até mesmo pela ausência de instituições de ensino superior nos municípios em estudo, associado com a dificuldade de transporte até a capital do Estado.

Estes dados refletem também na renda do responsável pelo domicilio, índice importante no estudo da população, pois indica a posição do individuo na sociedade, determinando, como expressa Ribeiro (1998, p. 174) "seu acesso aos bens e serviços à disposição dos habitantes da cidade" além de 
apresentar estreita relação com a educação, pois quanto maior o grau de escolaridade maiores as oportunidades de emprego.

No âmbito geral da bacia esta relação é bem evidente, pois $64 \%$ dos moradores dependem da renda de até dois salários mínimos (IBGE, 2000). Deste total, $10,7 \%$ dos responsáveis pelos domicílios não apresentam renda fixa e 33,0\% recebem apenas um salário mínimo, o que totaliza mais de 360mil habitantes sobrevivendo com condições precárias em termos de rendimento.

Constata-se que mais de $50 \%$ dos moradores dependem de renda de até um salário mínimo, nos municípios de Carira $(56,1 \%)$, Pinhão $(50,6 \%)$, Simão Dias (61,5\%), Macambira $(59,2 \%)$, pertencentes ao Alto-baixo curso; Lagarto $(51,1 \%)$, São Domingos $(62,8 \%)$, Campo do Brito $(51,3 \%)$ e Areia Branca (56,3\%), do Médio-baixo curso; e Itaporanga (58,4\%) no Baixo curso. Esta realidade pode estar associada à baixa escolaridade e a baixa oferta de emprego.

Isto implica em um acesso limitado à saúde, lazer, educação, dentre outros para o cidadão e seus dependentes, refletindo em uma baixa qualidade de vida. Revelam também que o crescimento da população na bacia não foi acompanhado por um crescimento econômico que possibilitasse a inserção destes cidadãos no mercado de trabalho.

Esta população com carência em termos de escolaridade, baixa renda e poucas perspectivas de ascensão social e econômica, muitas vezes é levada a ocupar áreas de baixa assistência a saúde, com pouco ou nenhum serviço de saneamento básico, repercutindo em uma maior pressão sobre os recursos hídricos locais. Um ciclo vicioso de pouca possibilidade de ascensão social associada a ausência de serviços de distribuição de água tratada, ausência de serviços de coleta e tratamento de esgotos e de maior susceptibilidade a contaminação por doenças de veiculação hídrica.

Voltando a atenção para a realidade do saneamento, constata-se que a bacia não foge ao padrão brasileiro e especificamente ao nordestino de uma precariedade no tocante às condições de abastecimento de água e principalmente de coleta e tratamento dos efluentes sólidos e líquidos, que embora tenham sido ampliadas nas últimas décadas, ainda grande parte da 
população não está contemplada com um sistema de saneamento básico adequado.

Com relação ao abastecimento de água, $84,1 \%$ das famílias cadastradas na bacia apresentam seus domicílios ligados à rede pública de abastecimento, enquanto que $11,6 \%$ são abastecidas por poços ou nascentes e 4,3\% por outras formas (SIAB, 2007).

No entanto, este percentual encontra-se elevado devido ao fato do município de Aracaju elevar a média da bacia. Ao ser analisada a realidade de cada município, constata-se que em sete deles, o sistema de abastecimento via rede pública não ultrapassa $66 \%$ das famílias cadastradas, o que totaliza mais de vinte e quatro mil famílias sem abastecimento adequado.

Os índices mais precários são identificados em Simão Dias (50,3\%), Itaporanga d'Ajuda (58,3\%), Lagarto (58,4\%), Carira (64,0\%), Macambira $(62,9 \%)$ e Areia Branca (61,5\%). Nestas localidades o abastecimento via poço ou nascente é elevado como em Itaporanga d'Ajuda $(36,1 \%)$, Lagarto $(37,4 \%)$, Macambira (23,8\%) e Areia Branca (36,4\%). Nos municípios de Simão Dias e Carira há um elevado percentual de famílias abastecidas por outras formas que não as citadas anteriormente, 36,2\% e 27,5\%, respectivamente.

Os municípios que melhor atendem as famílias com abastecimento via rede pública são Aracaju (97,3\%), Pedra Mole (94,3\%) e São Domingos $(92,8 \%)$, o que garante, mesmo que parcialmente, um tratamento primário das águas nas estações de tratamento antes de serem distribuídas à população.

Este quadro torna-se preocupante a medida em que não há monitoramento constante das águas subterrâneas, nem quantitativo e nem qualitativo que abastecem estas comunidades e com o elevado percentual de fossas instaladas sem análise das condições topográficas e geológicas, há sempre uma possibilidade de contaminação.

Sobre o destino do lixo na bacia constata-se que $81,9 \%$ dos domicílios são contemplados com coleta pública do lixo, estando $12,2 \%$ do lixo produzido nos domicílios queimado ou enterrado e 5,8\% liberado a céu aberto. No entanto, a realidade acerca dos resíduos sólidos na bacia revela que não há 
destino final adequado para os mesmos, sendo estes jogados em lixões a céu aberto.

A rede de esgoto é mais abrangente apenas no município de Aracaju (67,5\%). As fossas predominam em Pedra Mole (98,6\% dos domicílios), Areia Branca (93,2\%) e São Domingos (92,0\%). Tanto o sistema de fossas como a liberação dos efluentes domésticos (águas negras) a céu aberto apresentam percentual elevado em Carira (75,6\% e 23,2\%, respectivamente), Simão Dias (46,2 \% e 16,7\%), Macambira (79,4\% e 13,4\%, respectivamente), São Cristóvão (58,9\% e 12,9\%) e Itaporanga (63,6\% e 16,4\%).

Pelo exposto constata-se que a maioria dos municípios da bacia apresentam sérios problemas em termos de qualidade do sistema de saneamento, pois tanto há deficiência em termos de abastecimento e de tratamento da água nos domicílios, quanto é elevado o percentual de domicílios que não apresentam coleta pública do lixo, nem sistema de esgoto instituído, merecendo destaque negativo para Carira, Simão Dias e Itaporanga.

Isto representa uma maior pressão sobre os recursos hídricos locais, em função da liberação direta de diversos tipos de efluentes sólidos e líquidos nos mananciais do recorte em estudo, bem como supressão da vegetação ciliar e/ou nativa local para fixação da população de baixa renda que geralmente ocupa as áreas periféricas e com ausência dos serviços básicos de saneamento e saúde.

Em outras palavras: a bacia sergipana do rio Vaza Barris apresenta de Alta a Média vulnerabilidade hídrica em sua maior parte, imposta pelos condicionantes ambientais, associada a uma elevada vulnerabilidade social, resultante de processos de exclusão social.

Estes dados corroboram com o exposto por Marengo (2008) ao afirmar que os estados do Nordeste apresentam baixos indicadores sociais denotando uma maior vulnerabilidade socioambiental local.

No contexto desta análise, compreende-se que a população local, principalmente a de baixa renda é a mais vulnerável em virtude da baixa qualidade de vida e das limitações apresentadas em termos de sustentabilidade social, econômica e ambiental. 
Este e outros indicadores devem ser utilizados para uma análise mais completa da vulnerabilidade na bacia, a exemplo dos índices de qualidade das águas, percentual de degradação das matas ciliares, atuação das políticas públicas, dentre outros. Todos estes dados poderiam compor uma matriz de riscos e vulnerabilidade socioambiental, que poderá ser objeto de novos estudos. No entanto, muitos destes dados inexistem, sendo necessários estudos específicos para diagnosticá-los, que podem, a partir deste trabalho, ser, então estruturados.

\section{Considerações Finais}

Considerando os indicadores escolhidos e a escala de trabalho utilizada foi possível obter um olhar integrado das fragilidades naturais e da vulnerabilidade hídrica na bacia, embora não esteja salvo de generalizações dado ao pequeno nível de detalhamento, podendo ter encoberto realidades $e$ usos diversos.

A associação dos indicadores escolhidos compôs um quadro acerca da vulnerabilidade hídrica, demonstrando que as limitações naturais impostas pelo ambiente (principalmente as relativas aos aspectos hidrogeológicos, pedológicos e climáticos) podem ser potencializadas pelas pressões antrópicas, traduzidas aqui pelas formas de utilização das terras e pelo elevado grau de vulnerabilidade social associadas às deficiências no setor de saneamento presentes.

Estes, associados às limitações naturais impostas pelos condicionantes geoambientais, a exemplo do elevado grau de erodibilidade dos solos, bem como a degradação da cobertura vegetal e a ineficácia dos serviços básicos de saneamento, imprimem uma forte tensão à qualidade dos corpos hídricos, culminando em um elevado grau de vulnerabilidade hídrica principalmente no Alto-baixo curso da bacia (Unidades 401 a 404).

No Médio-baixo curso, alguns destes problemas se repetem, a exemplo da ausência de uma infra-estrutura hídrica e de esgotamento sanitário que contemple a população local, como também a ocorrência de um elevado grau de degradação da cobertura vegetal. 
No Baixo curso, embora apresente uma base física que denote uma menor vulnerabilidade hídrica, outros fatores pressionam os recursos hídricos, contribuindo para as mudanças na dinâmica da paisagem local. Em Aracaju, estas pressões relacionam-se com a expansão imobiliária, loteamentos e segundas residências, que nem sempre são acompanhadas com o crescimento da infra-estrutura local. No município de São Cristóvão os empreendimentos de carcinicultura e a poluição hídrica por esgotos domésticos tornam-se fortes tensores antrópicos. Em Itaporanga d'Ajuda, a pecuária exerce pressão sobre a vegetação nativa com degradação elevada das matas ciliares.

Esta realidade necessita ser considerada demonstrando que não há não apenas a vulnerabilidade hídrica, mas também vulnerabilidade social. Isto pressupõe a adoção de medidas mitigadoras, a exemplo do uso mais racional dos recursos hídricos locais; programas de recuperação de nascentes; programas locais de combate a pobreza; melhorias no sistema de saúde, educação e ampliação das possibilidades de retorno econômico e social que dependem de políticas públicas efetivas.

\section{Referências Bibliográficas}

AUGÉ, Miguel. Vulnerabilidad de acuiferos: conceptos e métodos. Universidad de Buenos Aires. 2005. Disponível em: http://tierra.rediris.es/hidrored/ebvulnerabilidad.html. Acesso em: 25/07/2011

BOTELHO Rosangela G. M.; SILVA, Antonio Soares da. Bacia hidrográfica e qualidade ambiental. In: VITTE, Antonio Carlos; GUERRA, A.J.T. Reflexões sobre a geografia física no Brasil. Rio de Janeiro: Bertrand Brasil, 2004, p. 153- 192.

CAMPOS, Nilson. Gestão de águas: novas visões e paradigmas. In: CAMPOS, Nilson; STUDART, Ticiana. Gestão das Águas: princípios e práticas. Porto Alegre: ABRH, 2003, p. 19-26.

CARRERA-FERNANDEZ, José; GARRIDO, Raymundo José. Economia dos recursos hídricos. Salvador: EDUFBA, 2002.

COHIDRO. Companhia de Desenvolvimento de Recursos Hídricos e Irrigação de Sergipe. Precipitação Pluviométrica do município de Itaporanga d'Ajuda. 1985-1997. 
CONFALONIERI, Ulisses E. C. Terra Livre, Ano 19 - vol. I - n. 20, jan/jul. São Paulo, 2003, p. 193-204.

CREPANI, Edison et.al. Curso de Sensoriamento Remoto aplicado ao Zoneamento Ecológico-Econômico. Metodologia desenvolvida para subsidiar o Zoneamento Ecológico-Econômico e capacitar os técnicos dos Estados da Amazônia Legal. São José dos Campos: INPE, 1996. Disponível em: http://mtcm12.sid.inpe.br/col/sid.inpe.br/sergio/2004/05.13.15.34/doc/publicacao.pdf.

Acesso em 30/07/2011.

CPRM. Projeto Cadastro da Infra-Estrutura Hídrica do Nordeste: Estado de Sergipe. Aracaju: CPRM, 2002.

CUNHA, Raimundo G.L. Estudos de disponibilidade hídrica nas unidades de balanço da bacia hidrográfica do rio Vaza Barris. SEPLANTEC/SRH: Sergipe, 2001.

Estudos de disponibilidade e demanda de água nas unidades de balanço das bacias hidrográficas do estado de Sergipe. Vol. 15. SEPLANTEC/SRH: Sergipe, 2002.

EMPRESA BRASILEIRA DE PESQUISA AGROPECUÁRIA - EMBRAPA. Levantamento Exploratório e Reconhecimento dos Solos do Estado de Sergipe. Recife: SUDENE, 1973.

Sistema de Classificação de Solos. 2ed. Brasília: EMBRAPA Produção de Informação; Rio de Janeiro: EMBRAPA Solos, 2006.

EMDAGRO. Empresa de Desenvolvimento Agropecuário de Sergipe. Precipitação Pluviométrica do município de Carira. 1985/1997.

$1985 / 1997$.

Precipitação Pluviométrica do município de Frei Paulo. $1985 / 1997$.

Precipitação Pluviométrica do município de Campo do Brito. $1985 / 1997$.

Precipitação Pluviométrica do município de Itabaiana.

Precipitação Pluviométrica do município de Itaporanga d'Ajuda. 2001/2009.

GARCIAS, Carlos Mello; SANCHES, Alexandre Martinho. Vulnerabilidades sócioambientais e as disponibilidades hídricas urbanas: levantamento teóricoconceitual e análise aplicada ã região metropolitana de Curitiba - PR. Revista de pesquisa em arquitetura e urbanismo programa de pós-graduação do departamento de arquitetura e urbanismo. São Paulo: EESC-USP, 2009, p. 96-112.

HOGAN, Daniel Joseph, et. al. Urbanização e Vulnerabilidade socioambiental: o caso de Campinas. In: HOGAN, Daniel Joseph, et. al. Migração e Ambiente nas Aglomerações Urbanas. Campinas: UNICAMP, 2001. p. 397-418. Disponível em : http://www.nepo.unicamp.br/. Acesso em: 25/07/2011 
INSTITUTO BRASILEIRO DE GEOGRAFIA E ESTATÍSTICA (IBGE). Censo Demográfico. Sergipe, 2000.

\section{Censo Agropecuário. Sergipe, 2006.}

Mapeamento de Solos do IBGE. Bahia, 2007.

JICA - JAPAN INTERNATIONAL COOPERATION AGENCY Estudo sobre desenvolvimento de recursos hídricos no estado de Sergipe. Aracaju: SEPLANTEC, 2000.

LANNA, A. E. L. Gerenciamento de bacia hidrográfica: aspectos conceituais e metodológicos. Brasília: Instituto Brasileiro do Meio Ambiente e dos Recursos Naturais Renováveis, 1995.

LEAL, Antonio Cezar. Meio ambiente e urbanização na microbacia do Areia Branca - Campinas/SP. Instituto de Geociências e Ciências Exatas. Rio Claro: Universidade Estadual Paulista. Dissertação de Mestrado, 1995.

. Gestão das Águas no Pontal do Paranapanema/SP. Instituto de Geociências. Campinas: Universidade Estadual de Campinas. Tese de Doutorado. 2000.

LEFF, Enrique. Saber ambiental: sustentabilidade, racionalidade, complexidade, poder. Tradução: Lúcia M.E. Orth. 7.ed. Petrópolis: Vozes. Rio de Janeiro, 2009.

MACHADO, Carlos José Saldanha. Recursos Hídricos e cidadania no Brasil: limites, alternativas e desafios. Ambiente e Sociedade. Vol.VI, n.2, jul/dez, 2003, p.122-136.

Gestão de Águas Doces. Rio de Janeiro: Interciência, 2004.

MAGALHÃES JÚNIOR, Antônio Pereira. Indicadores ambientais e recursos hídricos: realidade e perspectiva para o Brasil a partir da experiência francesa. Rio de Janeiro: Bertrand Brasil, 2007.

MARENGO, Jose A. Vulnerabilidade, impactos e adaptação à mudança do clima no semi-árido do Brasil. Parcerias Estratégicas. n.27. Brasília, 2008, p. 149-176.

MENDONÇA, Francisco. Geografia socioambiental. In: MENDONÇA, Francisco; KOZEL, Salete (orgs). Elementos de epistemologia da geografia contemporânea. Curitiba: UFPR, 2004, p. 121-144.

MENDONÇA FILHO, J.C. Agricultura e Meio Ambiente na bacia do rio Cotinguiba/SE. Projeto de Mestrado. São Cristóvão: NPGEO/UFS, 2000.

PINTO, Josefa Eliana $S$ de S. Os reflexos da seca no Estado de Sergipe. NPGEO: UFS, 1999.

PNUD. Atlas do Desenvolvimento Humano no Brasil. 2000.

ROSS, Jurandyr L. S. O registro cartográfico dos fatos geomórficos e a questão da taxonomia do relevo. In: CHRISTOFOLETTI, A., BECKER, B.K., DAVIDOVICH, F.R. e GEIGER, P.P. (org). Geografia e meio ambiente no Brasil. São Paulo: Hucitec, 1994. 
SEPLANTEC/SRH. Superintendência de Recursos Hídricos. Atlas Digital sobre recursos hídricos. Sergipe. 2004. SEPLANTEC. SECRETARIA DO PLANEJAMENTO E DA CIÊNCIA E TECNOLOGIA. Perfis Municipais. Sergipe, 2002.

. Precipitação Pluviométrica do município de Aracaju. 1970/2000.

SIAB - Sistema de Informação de Atenção Básica. Consolidado das famílias cadastradas no ano de 2007. Secretaria de Assistência a Saúde: Secretaria Estadual de Saúde. Sergipe, 2007.

SILVA, Demetrius David da.; PRUSKI, Fernando Falco. Gestão de Recursos Hídricos: aspectos legais, econômicos, administrativos e sociais. Viçosa: Universidade Federal de Viçosa, 2005.

SUDENE. Precipitação Pluviométrica do município de Frei Paulo. 1970/1984.

TAGLIANI, Carlos R.A. Técnica para Avaliação da Vulnerabilidade Ambiental de Ambientes Costeiros utilizando um Sistema Geográfico de Informações. Anais XI SBSR, Belo Horizonte, Brasil, 05 - 10 abril 2003, INPE, p. $1657 \quad$ - 1664.10 Disponível http://www.praia.log.furg.br/Publicacoes/2003/2003c.pdf. Acesso em 30/07/2011.

TUNDISI, José Galizia. Água no século XXI: enfrentando a escassez. 2.ed. São Paulo: Rima, 2005. 